\title{
PERFIL CONSTRUTIVO DAS FORTIFICAÇÕES PORTUGUESAS DA CAPITANIA DE PERNAMBUCO DE 1630 ATÉ 1654: Período de ocupação holandesa
}

CONSTRUCTIVE PROFILE OF PORTUGUESE FORTIFICATIONS IN CAPITANIA OF PERNAMBUCO FROM 1630 TO 1654:

Dutch occupation period

\author{
Manuela Xavier Gomes de Matos ${ }^{1}$ \\ manumatos@uol.com.br \\ Paulo Martin Souto Maior ${ }^{2}$ \\ pmsmaior@yahoo.com
}

\section{RESUMO}

O perfil construtivo de três fortificações da antiga Capitania de Pernambuco nas primeiras décadas do século XVII, período anterior à ocupação holandesa, revelou, através de dois remanescentes (Forte de São Francisco da Barra, de 1606, e Forte de São Francisco de Olinda, de 1620) e de iconografias (Forte de São Jorge, de 1590), que essas construções foram influenciadas por modelos descritos em tratados de fortificação europeus da época. Além do mais as adaptações à realidade de material, mão de obra, recursos e postura colonizadora impuseram certas restrições e adaptações. Identificar essas transformações foi o objetivo principal desta pesquisa.

Palavras chaves: Fortificações, século XVII, Pernambuco.

\footnotetext{
${ }^{1}$ Discente, Programa de Pós-graduação em Arqueologia, UFPE.

${ }^{2}$ Departamento de Arqueologia, UFPE.
} 


\section{ABSTRACT}

The constructive profile of three fortifications of the Captaincy of Pernambuco in the first decades of the 17th Century, before the Dutch occupation, revealed, through two remnants (Forte de São Francisco da Barra, 1606, and Fort de São Francisco de Olinda, 1620) and of iconographies (Fort de São Jorge, 1590), that these constructions were influenced by models described in European fortification treaties. Moreover, adaptations to the reality of material, labor, resources and colonizing posture have imposed certain restrictions and adaptations. Identifying these transformations was the main objective of this research.

Keywords: Fortifications, 17th century, Pernambuco.

\section{EFICÁCIA BÉLICA}

No presente estudo, ainda foi incorporada a noção de Eficácia Bélica, que acrescentou aos conceitos de Estruturas de Defesa e de Sistema Defensivo as variáveis Tipologia de Fortificação, Modelo de Configuração Geométrica e Grau de Obediência ao Modelo Europeu.

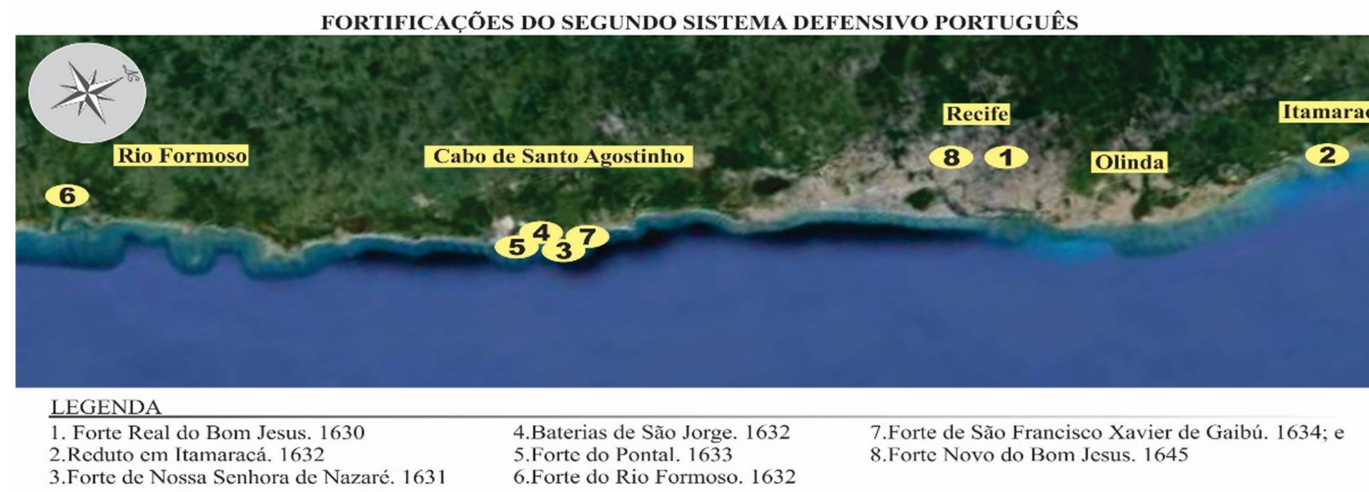

Figura 1. Localização das fortificações construídas pelo colonizador português durante a invasão holandesa. Do conjunto de oito fortificações, restaram três: o Forte Real do Bom 
Jesus, de 1630; o Forte Nossa Senhora de Nazaré, de 1630; e o Forte de São Francisco Xavier de Gaibu, de 1634.

Dentre as oito fortificações do segundo sistema defensivo português em Pernambuco, apenas três puderam ser estudadas: o Forte Real do Bom Jesus, construído em 1630; o Forte Nossa Senhora de Nazaré, construído em 1630; e o Forte de São Francisco Xavier de Gaibu, construído em 1634.

\section{Presença holandesas em Pernambuco de 1630 a 1654}

\section{Forte Real do Bom Jesus. 1630}

O Forte Real do Bom Jesus, localizado no atual bairro de Casa Amarela, na cidade do Recife, foi construído pelos colonizadores portugueses a partir de 1630 (ver Figura 2). Da antiga fortificação há apenas vestígios arqueológicos. Durante pesquisas arqueológicas nas décadas de 1960 e 1980 foram identificados trechos do fosso, a base das muralhas e do terrapleno. Os remanescentes do Forte estão inseridos em área urbana, totalmente antropizada.

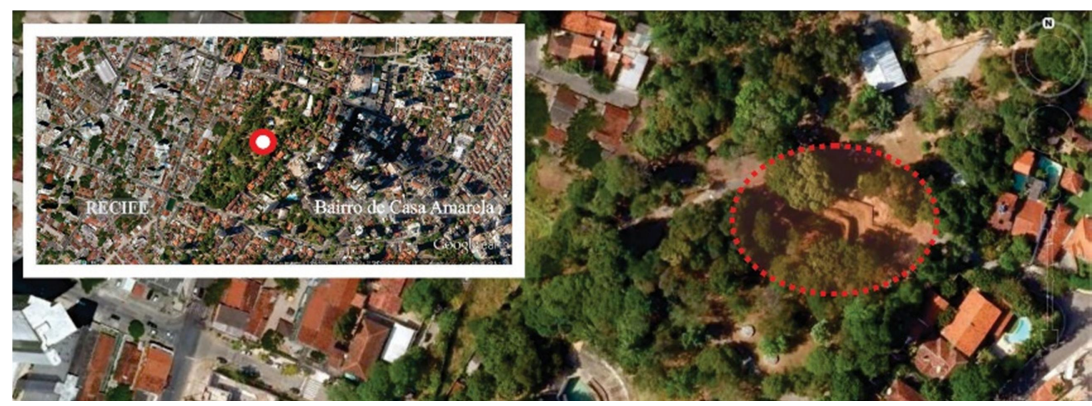

Figura 2. $\quad$ L ocalização do Forte Real do Bom Jesus, no município de Recife, no Estado de Pernambuco. 


\section{Cronologia}

Em 1630, depois que todas as fortificações de Olinda e da povoação do Recife foram dominadas pelos holandeses, Matias de Albuquerque construiu o Forte Real do Bom Jesus. O Forte representou um campo fortificado de resistência à dominação holandesa. Seu objetivo era isolar os holandeses no litoral, atrapalhando seu acesso ao interior. O Forte era pobremente artilhado, mas resistiu a cinco anos de constantes ataques holandeses. Foi construído em terra, com formato irregular, supostamente com planta de Cristóvão Álvares. Era uma obra considerada rústica, mas de extraordinária solidez. No final da década de 1960, o Laboratório de Arqueologia da Universidade Federal de Pernambuco realizou algumas pesquisas arqueológicas no sítio do Forte. Foram identificados trechos do fosso, a base das muralhas e do terrapleno, (Menezes. 1986: p. 109-110; Albuquerque, 1988: p.33).

\section{Configuração Geométrica}

O Forte Real do Bom Jesus é uma fortificação com planta de formato de polígono irregular. Os principais itens que compõe a fortificação são: reparo onde estão baluartes poligonais de formato irregular (alguns tem faces e flancos, outros, só apresentam faces) e a cortina. O reparo conforma o terrapleno com parapeito ao redor e entre as obras externas estão fosso e barreiras em formato de linhas. 
Figura 3. Planta do Forte Real do Bom Jesus (1635). Arquivo Geral do Reino (Haia). Buitenlandse Kaarten n. 2.160 do Inventário Leupe. Publicada por Gonçalves de Mello, 1961.

Suas dimensões e proporções foram retiradas de um desenho geométrico presente na iconografia histórica (Figura 3), portanto, foram consideradas medidas relativas. Sua muralha devia ser inclinada, mas não há como inferir o caimento através dos desenhos disponíveis. Grosso modo, a fortificação mede 150 unidades de comprimento por 115 unidades de largura. Não sabemos, no entanto, o valor dessa unidade. Suas dimensões e proporções estão apresentadas nas Tabelas 1 e 2 e Figura 4, abaixo:

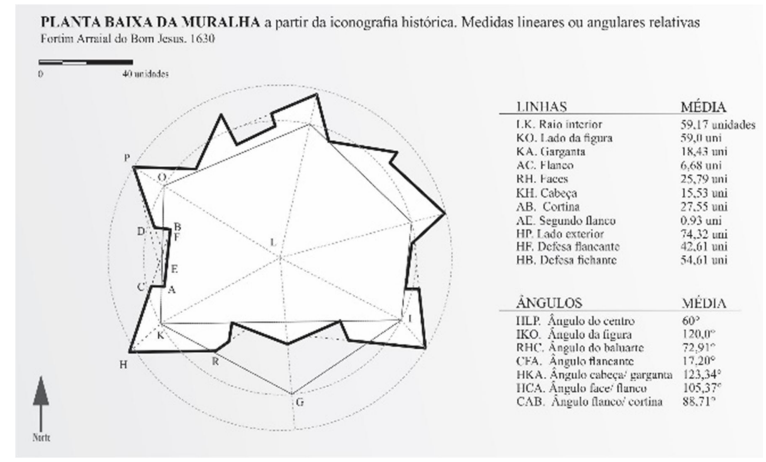

Figura 4. 2//Planta Baixa da Muralha do Fortim Arraial do Bom Jesus, com indicação das linhas e ângulos e suas medidas relativas, retiradas a partir de um projeto presente na iconografia histórica. 


\section{Escolha dos materiais construtivos}

Segundo os dados historiográficos e arqueológicos, o Forte Real do Bom Jesus foi construído em terra, utilizando o sistema da taipa de pilão. O material retirado do fosso que circundava a fortificação pode ter sido utilizado na construção da sua muralha (Albuquerque, 1999: p. 44-48). Diferentemente do material encontrado na planície litorânea, material arenoso, onde estava a povoação do Recife, o material disponível no local onde o Forte foi construído era sedimentar, não consolidado, de textura argilosa, integrante da planície costeira (Albuquerque, 1988: p. 10).

\begin{tabular}{|c|c|c|c|c|c|c|c|c|c|c|c|c|}
\hline & \multicolumn{12}{|c|}{ Lados } \\
\hline & 1 & 2 & 3 & 4 & 5 & 6 & 7 & 8 & 9 & 10 & 11 & Média \\
\hline Raio interior & 59,17 & 59,17 & 59,17 & 59,17 & 59,17 & & & & & & & 59,17 \\
\hline Lado da figura & 59,56 & 68,83 & 64,59 & 57,26 & 42,54 & 61,19 & & & & & & 59,00 \\
\hline Garganta & 18,41 & 16,09 & 31 & 26,48 & 13,63 & 15,7 & 11,13 & 15,03 & & & & 18,43 \\
\hline Flanco & 6,88 & 5,68 & 9,07 & 8,18 & 5,87 & 5,67 & 5,41 & & & & & 6,68 \\
\hline Face & 21,29 & 20,98 & 14,58 & 25,91 & 27,09 & 27,65 & 29,99 & 37,5 & 33,44 & 25,81 & 19,4 & 25,79 \\
\hline Cabeça & 18,26 & 15,95 & 14,9 & 15,44 & 13,1 & & & & & & & 15,53 \\
\hline Cortina & 24,88 & 47,01 & 19,73 & 18,58 & & & & & & & 90 & 27,55 \\
\hline Segundo flanco & 10,17 & 0,11 & & & & & & & & & & 0,93 \\
\hline Lado exterior & 79,88 & 85,45 & 75,69 & 58,85 & 66,68 & 79,36 & & & & & & 74,32 \\
\hline Defesa flancante & 43,9 & 55,82 & 16,72 & 52,02 & 46,31 & 40,91 & & & & & & 42,61 \\
\hline Defesa fichante & 53,29 & 55,93 & & & & & & & & & & 54,61 \\
\hline
\end{tabular}

Tabela 1. Medidas lineares utilizando unidade aleatória aferidas em projeto presente na iconografia histórica do Fortim Arraial do Bom Jesus. 


\begin{tabular}{|l|c|c|c|c|c|c|c|}
\hline & Ângulo & Ângulo & Ângulo & Ângulo & Ângulo & Ângulo & Média \\
\hline Ângulo do centro & $71,1^{\circ}$ & $60,4^{\circ}$ & $66,2^{\circ}$ & $57,8^{\circ}$ & $42,1^{\circ}$ & $62,3^{\circ}$ & $60,0^{\circ}$ \\
\hline Ângulo da figura & $116,7^{\circ}$ & $114,2^{\circ}$ & $113,3^{\circ}$ & $127,8^{\circ}$ & $130^{\circ}$ & $117,9^{\circ}$ & $120,0^{\circ}$ \\
\hline Ângulo do baluarte & $70,7^{\circ}$ & $69,1^{\circ}$ & $78,2^{\circ}$ & $84,9^{\circ}$ & $81,9^{\circ}$ & $52,6^{\circ}$ & $72,9^{\circ}$ \\
\hline Ângulo flancante & $25,0^{\circ}$ & $12,7^{\circ}$ & $13,9^{\circ}$ & & & & $17,2^{\circ}$ \\
\hline Ângulo cabeça/garganta & $125,5^{\circ}$ & $133,4^{\circ}$ & $111,1^{\circ}$ & $125,6^{\circ}$ & $121,1^{\circ}$ & & $123,3^{\circ}$ \\
\hline Ângulo face/flanco & $106,9^{\circ}$ & $115,1^{\circ}$ & $99,7^{\circ}$ & $119,4^{\circ}$ & $96,0^{\circ}$ & $95,1^{\circ}$ & $105,4^{\circ}$ \\
\hline Ângulo flanco/cortina & $94,2^{\circ}$ & $77,9^{\circ}$ & $90,1^{\circ}$ & $82,1^{\circ}$ & $90^{\circ}$ & $97,8^{\circ}$ & $88,7^{\circ}$ \\
\hline
\end{tabular}

Tabela 2. Medidas angulares aferidas em projeto presente na iconografia histórica do Fortim Arraial do Bom Jesus.

Estudos arqueológicos realizados na década de 1980 revelaram que a única estrutura arquitetônica conservada foi o fosso (ver Figura 5Figura 8) e que os principais materiais de construção empregados na construção da fortificação foram a argila local, madeira, seixos rolados e ferro (na forma de correntes e cravos) (Albuquerque, 1988: p. 22).

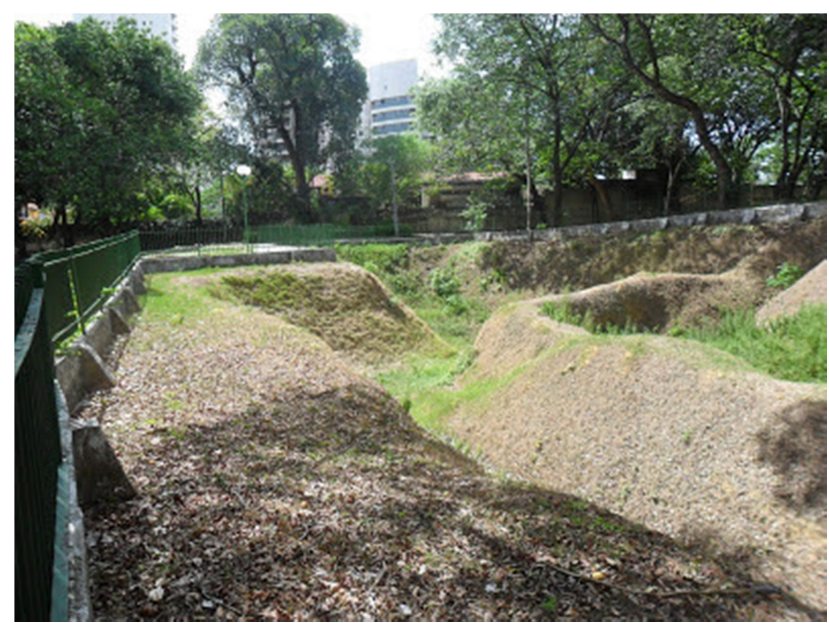

Figura 5. Remanescentes do fosso duplo do Forte Real do Bom Jesus depois da realização de escavações arqueológicas, nas décadas de 60, 80 e anos 2000. 


\section{Forte de Nossa Senhora de Nazaré. 1631}

O Forte Nossa Senhora de Nazaré foi construído pelos colonizadores portugueses em 1631. Como pode ser visto na Figura 6, está localizado na Vila de Nazaré, município de Cabo de Santo Agostinho, litoral sul do Estado de Pernambuco, distante cerca de $35 \mathrm{~km}$ do Recife. A estrutura do Forte encontra-se em ruínas, mas percebe-se intervenções contemporâneas que promoveram sua consolidação.

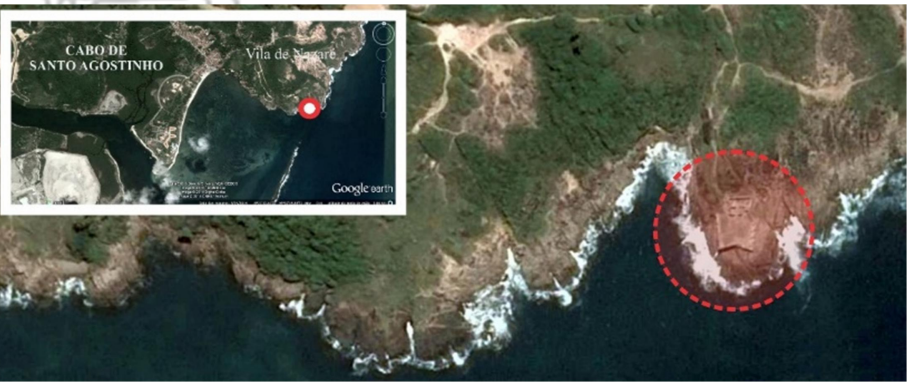

Figura 6. Localização do Forte Nossa Senhora de Nazaré, localizado na Vila de Nazaré, município de Cabo de Santo Agostinho no Estado de Pernambuco (modificado do Google earth, em 18.09.2014). Figura 7.

Como pode ser observado na Figura 6, o Forte Nossa Senhora de Nazaré está situado na entrada da Barra, no ponto baixo de uma enseada, numa área desocupada. Mas como foi construído sobre um trecho do afloramento rochoso, um pouco mais elevado que seu entorno, bem próximo ao mar. Apesar de não estar sujeito à ação das águas da chuva que escorrem sobre o afloramento, sua muralha está sujeita a ação das ondas do mar, principalmente as suas fachadas leste e sul. 


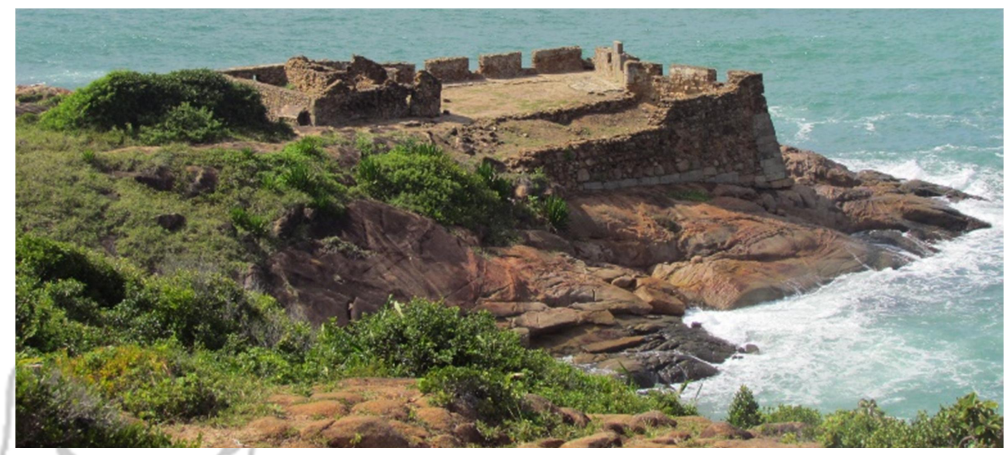

Figura 8. $\quad$ Forte Nossa Senhora de Nazaré, no Cabo de Santo Agostinho, litoral sul do Estado de Pernambuco.

\section{Dados históricos}

Foi construído em 1631 sobre a base sólida do rochedo, pelo Conde de Bagnoulo ${ }^{3}$ com o objetivo de defender a entrada da barra que dava acesso ao porto do Cabo de Santo Agostinho. Edificado em alvenaria de pedra, seu formato foi chamado de cauda de andorinha (Figura 10). Contava com sete peças de artilharia, além daquelas posicionadas nas baterias que lhe davam suporte, a partir de 1632 quando foram construídas. Duas das baterias contavam com duas peças de ferro cada (Coelho, 1981. p. 100). Em 1634, o Forte foi reparado, também pelo Conde Bagnuolo, e em 1635 foi conquistado pelos holandeses.

\footnotetext{
${ }^{3}$ Giovanni di San Felice, conde Bagnuoli, era um militar italiano. Nasceu em Nápoles em 1575 e morreu em Salvador em 1640. A serviço do rei da Espanha lutou contra os holandeses no nordeste brasileiro. Chegou ao Brasil em 1625, participou da retomada da Bahia aos holandeses, em 1631, junto com Matias de Albuquerque resistia aos holandeses em Pernambuco. Foi encarregado da defesa do Cabo de Santo Agostinho. Em 1640 voltou à Bahia, onde morreu em 26 de Agosto do mesmo ano. Fonte:geocities.
} 


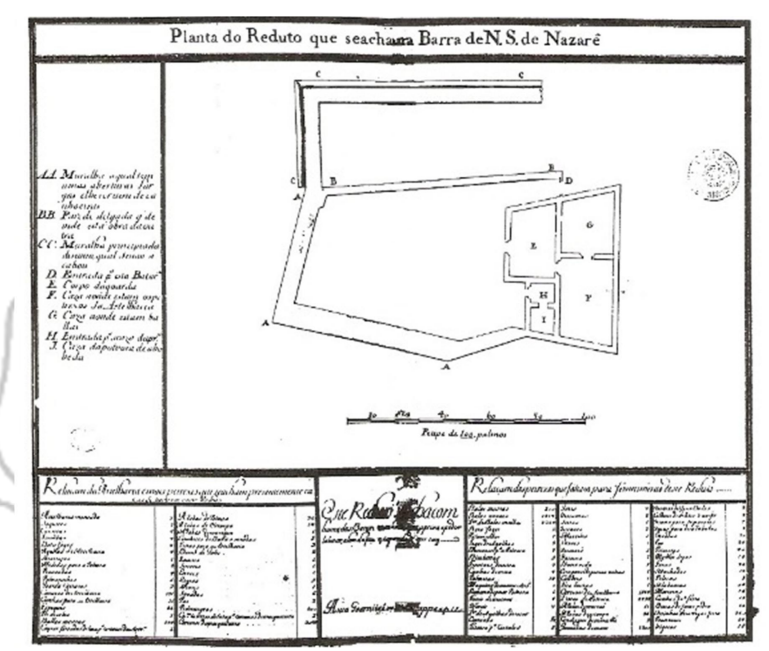

Figura 9. Forte de Nossa Senhora de Nazaré. Fonte: MENEZES. 1986. p. 106.

Em 1638, Maurício de Nassau avaliou que a fortificação era uma Bateria e que não poderia se defender no caso de inimigos desembarcarem no outro lado da mesma ponta, pois o forte é aberto por trás e, além disso, fica na parte baixa de dois montes. No "Relatório sobre o estado das Capitanias conquistadas no Brasil", de 1640 de Adriaen van der Dussen, o Forte de Nazaré foi apresentava contendo um hornaveque do lado do morro, em forma de tenalha e estava circundado por uma paliçada. Não há registro conhecido da existência de vestígios desses elementos.

Em 1645, a fortificação foi devolvida aos portugueses e em 1677, João Fernandes Vieira dá notícias ao Rei de que tinha começado obras de arremate na Fortaleza de Nossa Senhora de Nazaré (A.H.U., PE, Caixa 6, p. 232). Em 1763 estava com 
uma bateria caída. Em 1799, documentos defendiam que não se justificavam outros reparos, pois o acesso pela barra já era difícil para entrada dos inimigos. $\mathrm{O}$ forte foi alvo de pesquisa arqueológica pela Fundação do Patrimônio Histórico e Artístico de Pernambuco - Fundarpe e teve suas muralhas consolidadas pelo Instituto do Patrimônio Histórico e Artístico Nacional - IPHAN (Menezes. 1986. p. 107).

\section{Configuração Geométrica}

O Forte de Nossa Senhora de Nazaré é uma fortificação maciça, com formato de polígono irregular, quadrangular. Segundo Goldman, é uma fortificação do tipo Estrela, quando as cortinas são dobradas para dentro formando ângulos de $15^{\circ}$ com o lado da figura. Na sua parte posterior, há uma estrutura que não cumpre a função de defesa, por isso deve ter funções complementares, provavelmente uma estrutura voltada a dar suporte indireto às atividades militares. É composta por terrapleno e cortina, e sobre as cortinas leste, oeste e sul há um parapeito em pedra com canhoneiras. Sua muralha é inclinada, apresentando caimento médio de $78,51^{\circ}$. Grosso modo, a fortificação mede 23 metros de comprimento, 26 metros de largura e de 3,15 a 7 metros de altura, do solo atual até a parte superior da cortina. Suas dimensões e proporções estão apresentadas nas tabelas 3 e 4 e Figura 10, abaixo: 


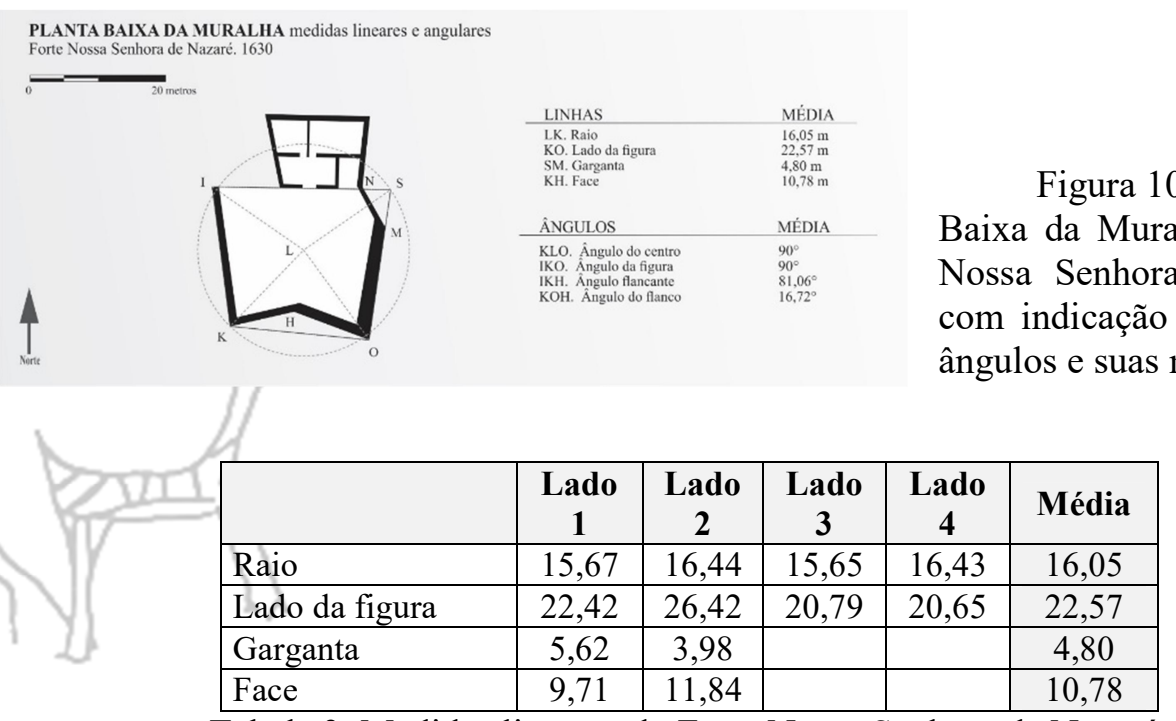

Tabela 3. Medidas lineares do Forte Nossa Senhora de Nazaré.

\begin{tabular}{|l|c|c|c|c|c|}
\hline & Ângulo & Ângulo & Ângulo & Ângulo & Média \\
\hline Ângulo do centro & $88,5^{\circ}$ & $110,7^{\circ}$ & $80,7^{\circ}$ & $80,1^{\circ}$ & $90,0^{\circ}$ \\
\hline Ângulo da figura & $92,6^{\circ}$ & $82,7^{\circ}$ & $81,7^{\circ}$ & $102,9^{\circ}$ & $90,0^{\circ}$ \\
\hline Ângulo flancante & $84,5^{\circ}$ & $77,6^{\circ}$ & & & $81,06^{\circ}$ \\
\hline Ângulo do flanco & $15,0^{\circ}$ & $18,4^{\circ}$ & & & $16,72^{\circ}$ \\
\hline
\end{tabular}

Tabela 4. Medidas angulares do Forte Nossa Senhora de Nazaré.

\section{Escolha dos materiais construtivos}

O Forte de Nossa Senhora de Nazaré está construído em alvenaria de pedra com argamassa de barro e cal. Verifica-se a presença de tijolos, em lugares isolados, possivelmente, fruto de alguma reforma posterior. Junto às fundações e no vértice entre a cortina Oeste e Sul, a alvenaria de pedra é composta por rochas talhadas de formato retangular, com tratamento de superfície. Nos demais trechos da 
fortificação a alvenaria é composta por rochas talhadas e não talhadas, sem tratamento de superfície, com formato irregular tendendo ao formato poligonal (ver Figura 11 e Figura 12).

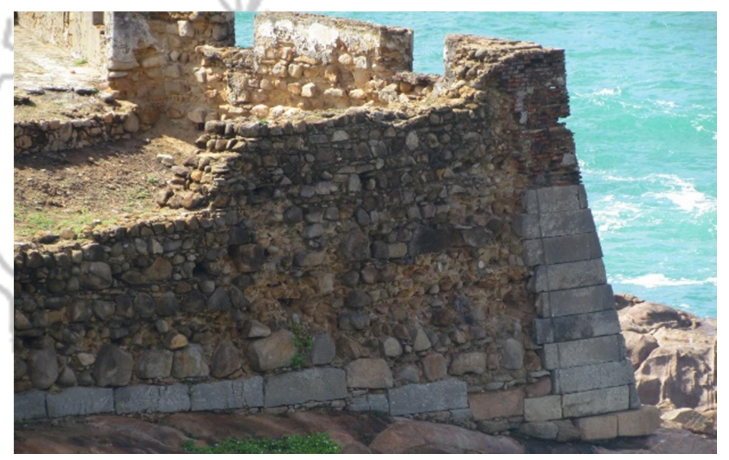

Figura 11. Cortina Oeste do Forte de Nossa Senhora de Nazaré onde se vêem os diferentes formatos e dimensões de rocha das alvenarias de pedra que compõe a fortificação.

Durante o levantamento físico foram identificados dois tipos de rochas utilizadas nas alvenarias da fortificação e além da rocha do afloramento rochoso sobre o qual a fortificação foi construída (Figura 12). Das rochas utilizadas na alvenaria, o primeiro tipo revelou, no exame macroscópico, ser composta por rocha muito bem selecionada, com grãos tamanho areia fina, sub-angulosos, de alta esfericidade, na cor creme e que não podem ser percebidos sem auxílio de lupa. Verificou-se ainda que a rocha contém $3 \%$ de impurezas. O segundo tipo de rocha é composto por rocha muito mal selecionada, com grãos tamanho grânulo, e areias grossa, média e fina, angulosos, de baixa esfericidade, na cor creme que podem ser percebidos sem auxílio de lupa. Quanto à presença de Carbonato de cálcio, verificou-se que as rochas do tipo 1 reagiu ao Ácido clorídrico ( $\mathrm{HCl}$ concentração de 10\%) 
liberando $\mathrm{CO}_{2}$, abundantemente por um curto espaço de tempo. Porém, a rocha do tipo 2 não reagiu ao Ácido clorídrico.

Finalmente, no exame macroscópico realizado na rocha do afloramento rochoso, foi identificada uma rocha pobremente selecionada, com grãos tamanho grânulo, e areias grossa e média, angulosos, de baixa esfericidade, na cor creme que podem ser percebidos sem auxílio de lupa. Quanto à presença de Carbonato de cálcio, verificou-se que a rocha reagiu ao Ácido clorídrico ( $\mathrm{HCl}$ concentração de 10\%) liberando $\mathrm{CO}_{2}$, abundantemente num primeiro momento e pouco num segundo momento.
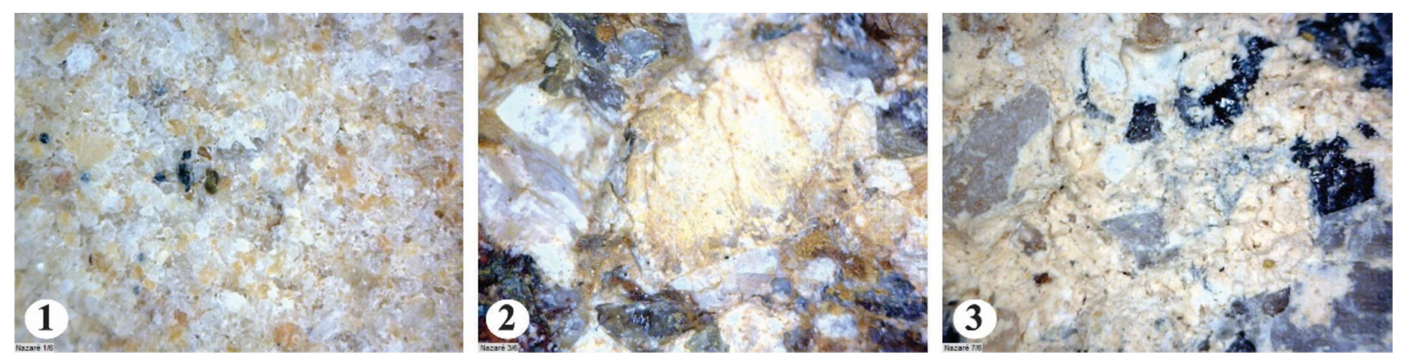

Figura 12. Rochas do Forte de Nossa Senhora de Nazaré. 1. Rocha tipo 1; 2. Rocha tipo 2. Rocha do afloramento rochoso. Imagem extraída a partir do Microscópio Digital portátil Dino-Lite PLUS, com aumento de 55 vezes.

A análise de Fluorescência de Raio-X permitiu identificar qualitativa e quantitativamente os elementos químicos que compõe as rochas identificadas (Gráfico 1). Os resultados evidenciaram que a rocha tipo 2 tem características semelhantes àquela do afloramento rochoso. Ambas as rochas contêm elevadas quantidades de Silício e presença significativa de Alumínio, Ferro e Potássio, além de vestígios de Cálcio. 
Amostras de rochas

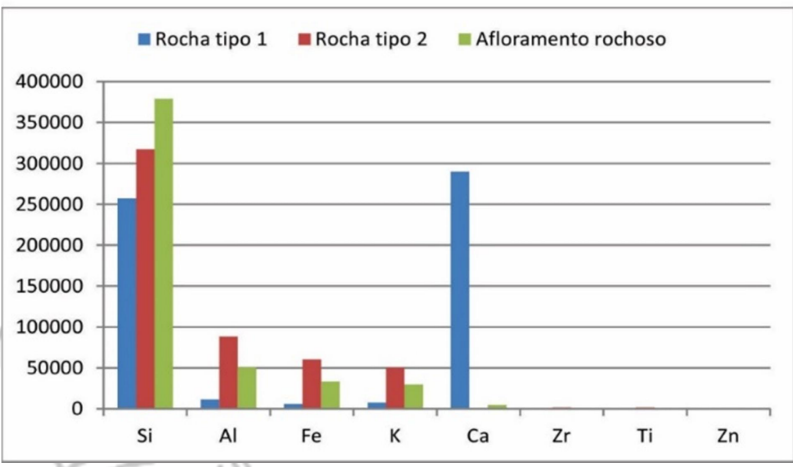

Gráfico 1. Resultados da análise de Fluorescência de Raio-X realizada nos tipos de rocha utilizados no Forte de Nossa Senhora de Nazaré. 1. Rocha tipo 1; 2. Rocha tipo 2. Rocha do afloramento rochoso.

Pelo contexto geológico típico da porção sul do litoral pernambucano, verifica-se que o Forte de Nossa Senhora de Nazaré foi construído sobre um afloramento de rochas da Formação Ipojuca, de origem vulco-sedimentar onde se encontram granitos, riolitos, basaltos e traquitos. A rocha do afloramento e a rocha tipo 2 podem ser da Formação Ipojuca. A rocha tipo 1, por sua vez, conta com elevadas quantidades de Silício e Cálcio, e vestígios de Alumínio, Ferro e Potássio, sugerindo tratar-se de arenito. Existem fontes de arenito que estão distantes de dois a oito quilômetros a Noroeste da fortificação. É uma grande ocorrência de arenitos da Formação Algodoais. Outra ocorrência de arenito são os arenitos da Formação Cabo, que aparecem em ocorrências esparsas a noroeste e em quantidade significativa, a oeste (Dantas \& Lima Filho, 2006). Há também uma fonte de arenito de praia (beachrocks) que está localizada ao longo da costa.

\section{Forte de São Francisco Xavier de Gaibu. 1634}

O Forte de São Francisco Xavier de Gaibu foi construído pelos colonizadores portugueses em 1634 sobre uma enseada, num afloramento de rocha, junto à praia. 
Está localizado na praia de Gaibu, município de Cabo de Santo Agostinho, litoral sul do Estado de Pernambuco, distante cerca de $33 \mathrm{~km}$ do Recife (Figura 13). A estrutura do Forte está em ruínas. Observam-se, no entanto, intervenções contemporâneas que promoveram sua consolidação, deixando dúvidas sobre a originalidade dos materiais de construção e seu agenciamento.

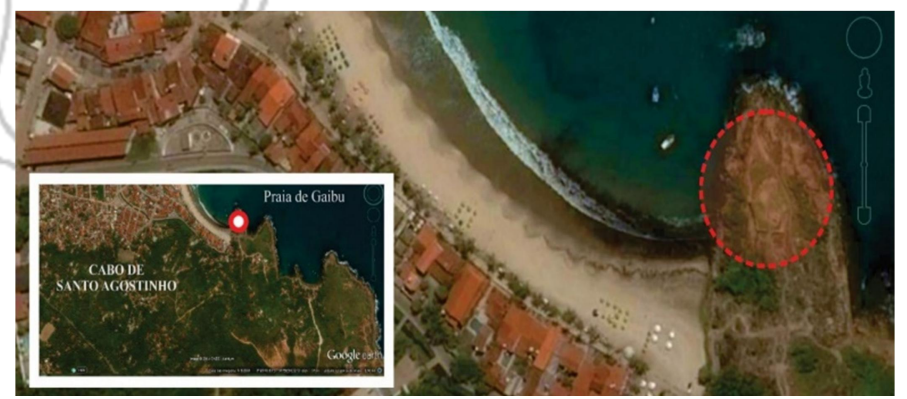

Figura 13. Localização do Forte de São Francisco Xavier de Gaibu, localizado na Praia de Gaibu, município de Cabo de Santo Agostinho no Estado de Pernambuco (modificado do Google earth, em 04.10.2014).

Esta fortificação ainda conta com um conjunto de muralhas, num nível mais abaixo, que além de garantir a estabilização do terreno, oferecia outros pontos para colocação de armas de fogo, (ver Figura 14).

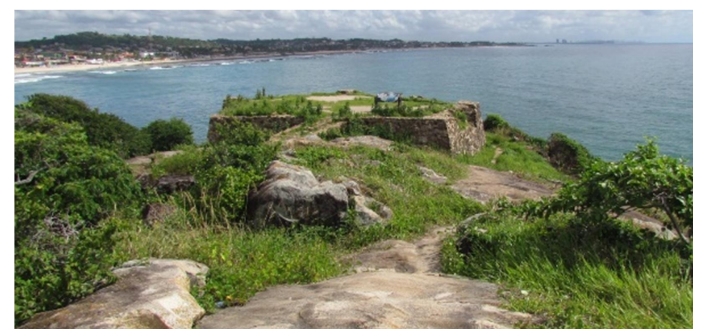

Figura 14. Forte de São Francisco Xavier de Gaibu construído pelos colonizadores portugueses em 1634 sobre uma enseada. 


\section{Dados históricos}

Em 1634, foram levantadas trincheiras nas praias de Gaibu e Itapoã por serem locais onde era fácil o desembarque (Coelho, 1981. p. 188). Uma dessas trincheiras teria sido o Forte de São Francisco Xavier de Gaibu. Em 1775 foi restaurado por ordem do Gov. Luiz Diogo Lobo da Silva. Em 1797 foi novamente reformado. Encontrava-se em ruínas e foi consolidado na década de 1970 (Menezes. 1986: p. 106; Albuquerque. 1999: p. 135) (ver Figura 15).

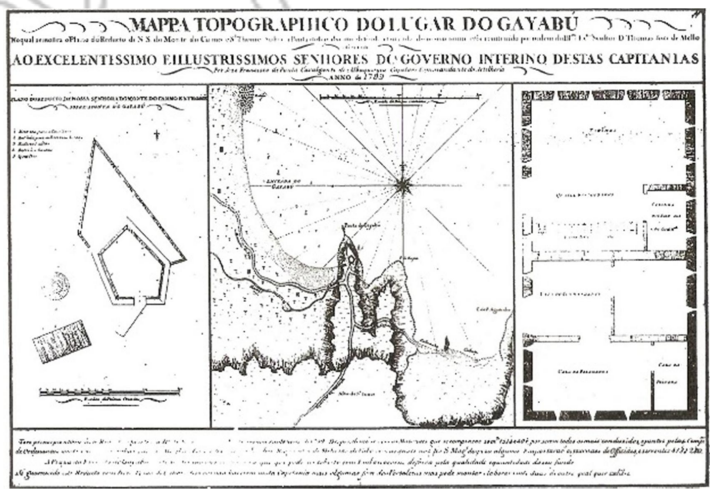

Figura 15. Planta de 1799 do Forte de São Francisco Xavier de Gaibu e sua localização. Fonte: MENEZES. 1986. p. 105.

\section{Configuração Geométrica}

O Forte São Francisco Xavier de Gaibu é uma fortificação com formato de polígono de cinco lados (pentágono) irregular. Por sua configuração parece uma Rocca italiana. Grosso modo, a fortificação mede 25,70 metros de comprimento, 20,90 metros de largura e de 1,50 a 5,50 metros de altura, do solo atual até a parte superior da cortina. Os principais itens que compõem a fortificação são cortina e terrapleno. Suas dimensões e proporções estão detalhadas nas Tabelas 5 e 6 e Figura 16. Sua muralha é inclinada, apresentando caimento médio de $78,68^{\circ}$. 

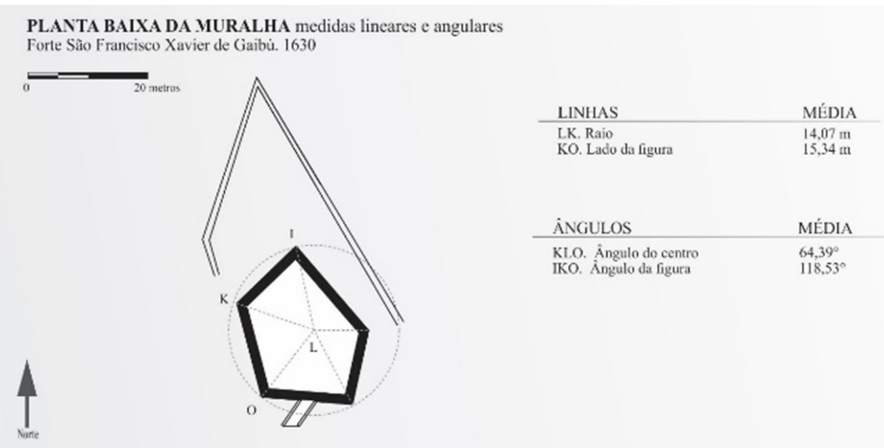

Figura 16. Planta Baixa da Muralha do Forte São Francisco Xavier de Gaibú, com indicação das linhas e ângulos e suas medidas.

\begin{tabular}{|l|c|c|c|c|c|c|}
\hline & Lado 1 & Lado 2 & Lado 3 & Lado 4 & Lado 5 & Média \\
\hline Raio interior & 13,65 & 14,37 & $9,16^{*}$ & 14,01 & 14,23 & 14,07 \\
\hline Lado da figura & 14,54 & 16,22 & 15,26 & 12,67 & 18,64 & 15,34 \\
\hline
\end{tabular}

Tabela 5. Medidas lineares aferidas em campo. Forte São Francisco Xavier de Gaibú.

\begin{tabular}{|l|c|c|c|c|c|c|}
\hline & Ângulo & Ângulo & Ângulo & Ângulo & Ângulo & Média \\
\hline Ângulo do centro & $65,4^{\circ}$ & $71,1^{\circ}$ & $58,8^{\circ}$ & $62,2^{\circ}$ & $102,4^{\circ}$ & $64,4^{\circ}$ \\
\hline Ângulo da figura & $109,4^{\circ}$ & $119,3^{\circ}$ & $126,9^{\circ}$ & $86,6^{\circ *}$ & $97,7^{\circ}$ & $118,5^{\circ}$ \\
\hline
\end{tabular}

Tabela 6. Medidas angulares aferidas em campo. Forte São Francisco Xavier de Gaibú.

\section{Escolha dos materiais construtivos}

O Forte de São Francisco Xavier de Gaibu está construído em alvenaria de pedra com argamassa (Figura 17). Apesar de haver dúvida quanto à originalidade de seus materiais construtivos, durante o levantamento físico foram identificados dois tipos de rochas utilizadas nas alvenarias da fortificação além da rocha do afloramento rochoso sobre o qual a fortificação foi construída, (Figura 18). 


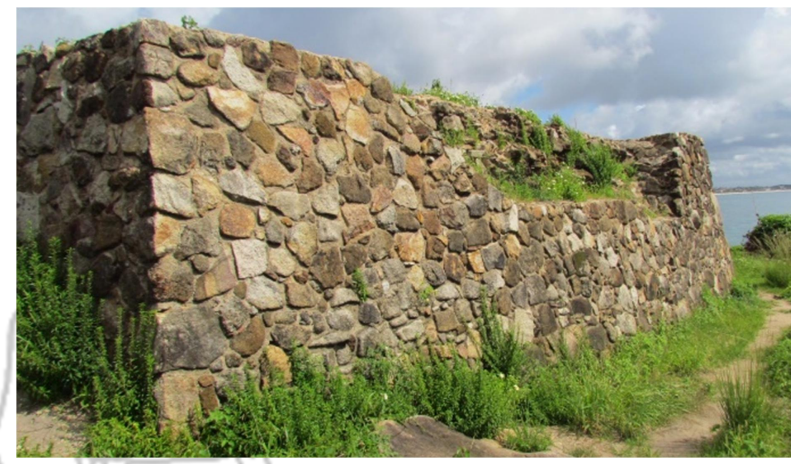

Figura 17. Cortina Sul do Forte de São Francisco Xavier de Gaibú onde se vê a homogeneidade do sistema construtivo utilizado.

Das rochas utilizadas na alvenaria, o primeiro tipo revelou, no exame macroscópico, ser composta por rocha bem selecionada, com grãos tamanho areia grossa e média, sub-angulosos, de baixa esfericidade, na cor creme e que podem ser percebidos sem auxílio de lupa. O segundo tipo de rocha é composto por rocha moderadamente selecionada, com grãos tamanho areia média e fina, subangulosos, de baixa esfericidade, na cor creme que podem ser percebidos sem auxílio de lupa. Quanto à presença de Carbonato de cálcio, verificou-se que as rochas da fortificação reagiram ao Ácido clorídrico ( $\mathrm{HCl}$ concentração de 10\%) liberando $\mathrm{CO}_{2}$, abundantemente por um curto espaço de tempo.

A rocha do afloramento rochoso, por sua vez, é uma rocha muito mal selecionada, com grãos tamanho grânulo e areias grossa e média, angulosos, de baixa esfericidade, na cor creme que podem ser percebidos sem auxílio de lupa. Quanto à presença de Carbonato de cálcio, verificou-se que a rocha não reagiu ao Ácido clorídrico ( $\mathrm{HCl}$ concentração de $10 \%$ ) portanto, não liberou $\mathrm{CO}_{2}$. 

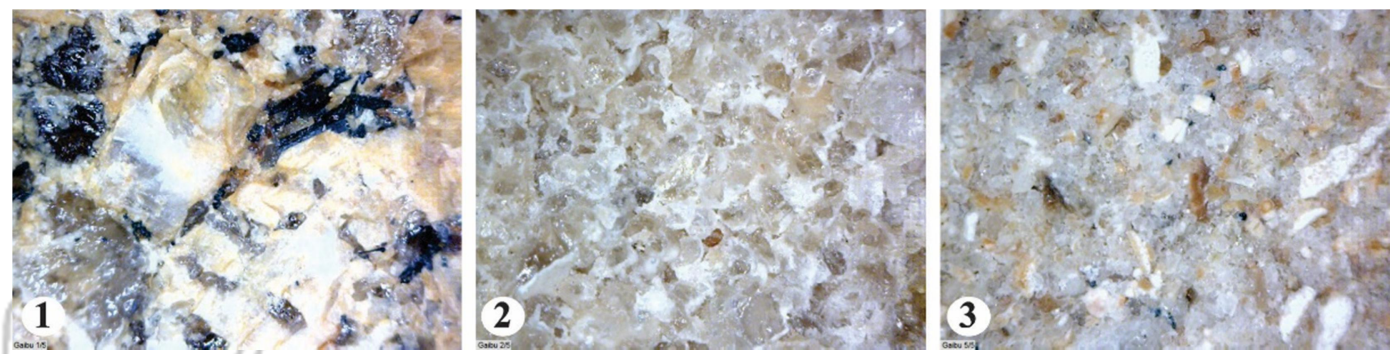

Figura 18. Rochas do Forte de São Francisco Xavier de Gaibú. 1. Rocha do afloramento rochoso; 2. Rocha tipo 1 do encontro entre as cortinas 2 e 3 (Nordeste e Noroeste). 3. Rocha do tipo 2, da cortina 4 (Oeste). Imagem extraída a partir do Microscópio Digital portátil Dino-Lite PLUS, com aumento de 55 vezes.

Em análise de Fluorescência de Raio-X foi possível identificar qualitativa e quantitativamente os elementos químicos que compõe as rochas identificadas (Gráfico 2). Os resultados evidenciaram que nenhuma das rochas é compatível com a rocha do afloramento rochoso. Ambas as rochas contêm elevadas quantidades de Cálcio e a rocha retirada do afloramento não tem quantidade significativa de Cálcio.

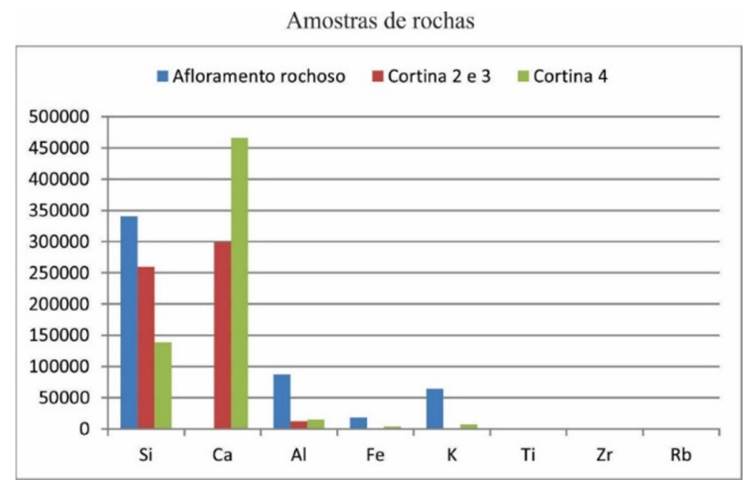

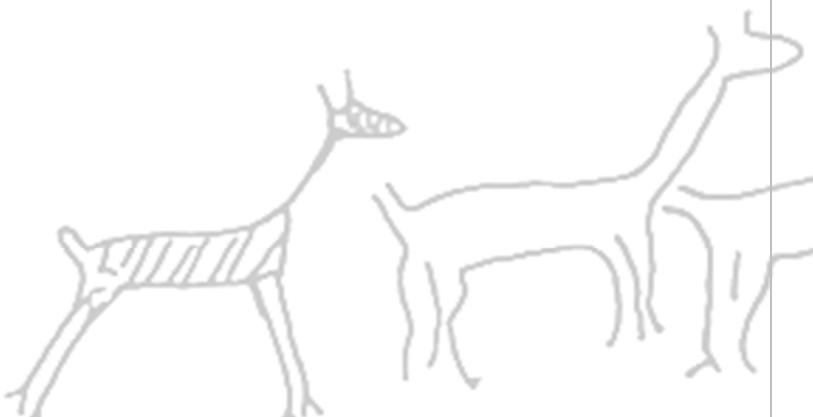

Gráfico 2. Resultados da análise de Fluorescência de Raio-X realizada nos tipos de rocha utilizados no Forte de São Francisco Xavier de Gaibu. 
Pelo contexto geológico típico da porção sul do litoral pernambucano, verifica-se que o Forte de São Francisco Xavier de Gaibu, assim como o Forte de Nossa Senhora de Nazaré, foi construído sobre um afloramento de rochas da Formação Ipojuca. Verificou-se, ainda, que foram utilizados dois diferentes tipos de rocha na alvenaria da fortificação. A rocha localizada no encontro entre as cortinas 2 e 3 conta com elevadas quantidades de Silício e Cálcio, e vestígios de Alumínio, sugerindo tratar-se de arenito. A rocha da cortina 4 tem elevada quantidade de Cálcio, significativa presença de Silício e vestígios de Alumínio, Ferro e Potássio. Também parece trata-se de arenito. A existência de dois tipos de arenito pode ser explicada de algumas maneiras: durante a sua construção, foram extraídas rochas de duas diferentes fontes de arenito localizadas no entorno da fortificação: uma delas, da Formação Algodoais, abrange uma área de 2 a $8 \mathrm{~km}$ a Noroeste da fortificação; a outra, da Formação Cabo, que oferece uma grande ocorrência de arenitos a oeste, e uma ocorrência esparsa a noroeste, uma a partir de $6 \mathrm{~km}$ da fortificação, a outra a partir de $8 \mathrm{~km}$, respectivamente (Dantas \& Lima Filho, 2006). Há também uma fonte de arenito de praia (beachrocks) que está localizada ao longo da costa.

\section{Resultados da Classificação Tipológica}

No caso das fortificações construídas de 1630 até 1654 na Capitania de Pernambuco, os aspectos da caracterização física considerados foram: formato, dimensões e proporções, modelos e inclinação dos muros. Estas são variáveis referentes ao conceito de Configuração Geométrica trabalhado nesta pesquisa. 
Nem um dos três fortes estudados apresentam as características mais marcantes dos tipos em questão, ou seja, tambores e muralhas altas para o tipo de transição e baluartes pentagonais para o tipo moderno. Nesse caso foram analisadas uma a uma, num olhar/mais aprofundado, a partir de uma análise comparativa entre as referências da caracterização física de ambos os tipos de fortificação europeias com os dados da caracterização física das fortificações construídas em Pernambuco nesse período. $\mathrm{Na}$ análise, verificou-se que essas fortificações apresentam tanto características da tipologia de Transição, como da Moderna.

O Forte Real do Bom Jesus conta com baluartes na sua configuração geométrica, e não apresenta altas muralhas ou tambores. No entanto não é evidente que possa ser considerado, de antemão, uma Fortificação Moderna. Dos seis baluartes existentes, como está esquematicamente desenhado na Figura 19, apenas o baluarte 06 apresenta formato pentagonal (o baluarte 01 é hexagonal; os baluartes 02 e 04 têm quatro lados; e, os baluartes 02 e 05 apresentam três lados, formato que pode categorizá-lo, inclusive, como um cavaleiro e não baluarte). Deve-se considerar ainda que não é possível afirmar, com clareza, qual o polígono regular ou irregular que deu origem à fortificação: polígono quadrangular, pentagonal ou hexagonal.

Observando, ainda, a Figura 19, pode-se ver que a ortogonalidade da cortina inferior em relação às cortinas lateral esquerda e lateral direita pode sugerir um polígono quadrangular; no entanto, o posicionamento dos baluartes 03 e 04 na 
parte superior da imagem, indicam um pentágono irregular; finalmente, se a figura original fosse um hexágono, seria um polígono mais próximo de um polígono regular. A incerteza sobre o formato geométrico não é uma característica da Fortificação Moderna, o formato irregular resultado da adaptação a condicionantes locais, sim, mas não parece ter sido o caso. No processo adaptativo, há indícios de regularidade no formato, nessa fortificação não há regularidade na sua configuração geométrica.

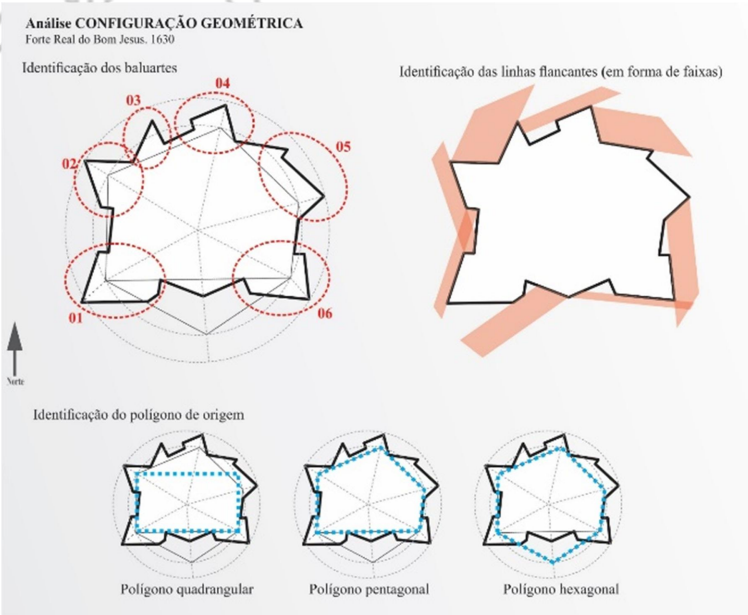

Figura 19. Análise da Configuração Geométrica do Forte Real do Bom Jesus, para realizar a sua classificação tipológica, entre Fortificação de Transição e Fortificação Moderna.

Continuando a análise do Forte Real do Bom Jesus, pode-se verificar que dentre as suas obras externas, as barreiras em formato de linhas que acompanham o recorte do Reparo, identificadas na iconografia, se parecem estruturalmente com barbacãs ${ }^{4}$. Estruturas desenvolvidas no âmbito das Fortificações de Transição.

\footnotetext{
${ }^{4}$ Barbacã são muralhas baixas localizadas no exterior da fortificação, formando uma segunda muralha.
} 
Finalmente, do ponto de vista da capacidade de defesa do Forte, o formato dos baluartes não propiciou a existência da defesa flancante plena, ou seja, nem todos os pontos da fortificação poderiam ser defendidos a partir dos flancos, pela ausência de flancos em alguns baluartes, como pode ser vista na figura acima. Enfim, por todos os argumentos construídos acima, não é possível classificar o Forte Real do Jesus como uma Fortificação Moderna; sua configuração geométrica tem semelhanças com aquelas fortificações construídas por portugueses nas suas colônias africanas, como por exemplo, na remodelação da fortaleza de Mazagão, em 1541, lembrando o processo de experimentação típico da Fortificação de Transição.

No que diz respeito ao Forte de Nossa Senhora de Nazaré e Forte de São Francisco Xavier de Gaibu, o primeiro apresenta uma configuração semelhante às torres marítimas típicas das Fortificações de Transição, como a Torre de Belém (torre medieval quadrangular conjugada a um baluarte moderno). A fortificação, em questão, apresenta um conjunto de espaços compartimentados, na sua parte posterior, agrupados num formato quadrangular, e desta estrutura partem muros inclinados, em direção ao mar, onde há canhoneiras. Como se pode observar na Figura 20, sua configuração geométrica não conta com baluartes modernos, conta apenas com a cortina fletida, proporcionando a defesa flancante de uma parte da fortificação. A partir do exposto, o Forte de Nossa Senhora de Nazaré pode ser considerado uma Fortificação de Transição. 


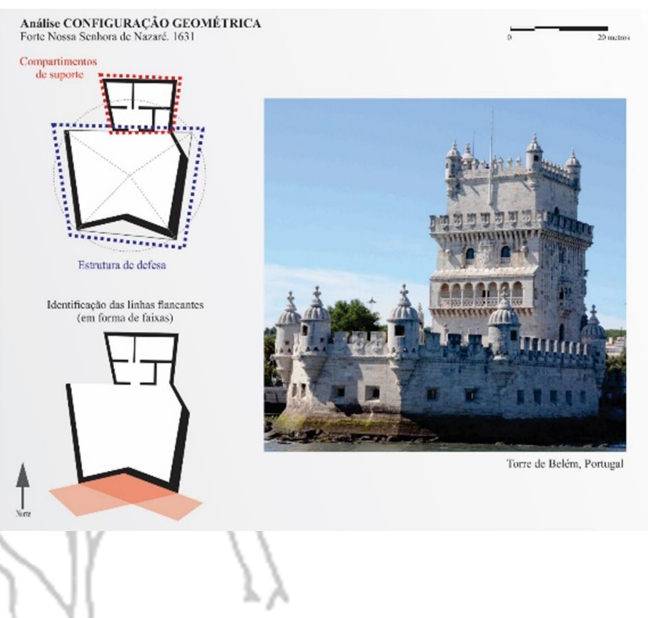

Figura 20. Análise da Configuração Geométrica do Forte de Nossa Senhora de Nazaré, para realizar a sua classificação tipológica, entre Fortificação de Transição e Fortificação Moderna. Fonte da imagem: site cidadeinformacao.pt.

Finalmente, a respeito do Forte de São Francisco Xavier de Gaibu, verifica-se que esta é uma fortificação com formato de pentágono irregular, cujas cortinas inclinadas conformam o terrapleno. Essa configuração apesar de não apresentar baluartes modernos, pentagonais, também não apresenta altas muralhas ou tambores. Deve-se, portanto, considerar seus outros atributos físicos: trata-se de uma fortificação maciça, com escarpa em talude, portanto, menos frágil, e consequentemente, mais favorável à defesa do ataque com armas de fogo, pois se configura como um corpo sólido. Conformação característica das Fortificações Modernas. No entanto, pela sua posição geográfica, no alto de uma escarpa, não está ao alcance dos tiros dos canhões de nenhuma embarcação inimiga, para atacála seria preciso vir por trás, pela terra. Continuando a análise, observa-se, ainda, que é uma fortificação com formas geométricas claras, apesar de ser um polígono irregular. Pela exiguidade do terreno, pode-se concluir que sua irregularidade foi resultado da adaptação ao terreno. Em síntese, pela ausência de elementos que a 
caracterizem como uma fortificação de Transição e pela sua estrutura de corpo solido, com reparo em talude, essa fortificação, pode ser classificada como uma Fortificação Moderna, de pequenas dimensões: como um fortim ou reduto.

\section{Resultado da Classificação quanto a modelos europeus modernos}

Dentre as fortificações estudadas, apenas uma foi classificada como moderna: Forte de São Francisco Xavier de Gaibu. Essa contudo não apresenta modelo que pode ser identificado em um único Tratado. O Forte apresenta um modelo simplificado, com formato poligonal (irregular), composto apenas por reparo, terrapleno e cortina. Esse modelo é citado por todos os autores, como, por exemplo, Scamozzi que apresenta o forte de campanha com formato triangular ou quadrangular a ser construído longe da fortaleza, de maneira que se for ocupado não cause problemas (Scamozzi, 1615. p. 187); e, Goldman que trata das pequenas obras, como os redutos, que são fortificações sem baluarte, que não se defenderiam inteiramente, pois apresentavam trechos que não poderiam ser vistos da própria obra, (Goldman, 1645. p. 3-12).

\section{Resultado da Classificação quanto à eficácia bélica}

A partir das informações que resultaram das análises apresentadas, podem ser fazer algumas reflexões sobre a efetiva transformação tecnológica nos processos construtivos das fortificações de Pernambuco da primeira metade do século XVII, durante a invasão holandesa. Verificou-se o retorno à utilização do tipo de Transição, apesar de já ter sido utilizado modelos do tipo moderno em período anterior, no primeiro Sistema Defensivo (século XVI e início do século XVII). 
Essa escolha significa a manutenção da baixa eficácia bélica nas fortificações da Capitania.

Numa análise mais detalhada, pode-se dizer com relação ao Segundo Sistema Defensivo Português (durante a permanência dos holandeses em Pernambuco), que das três fortificações analisadas, duas eram do tipo Fortificação de Transição e uma era do tipo Moderno. A escolha pela utilização do tipo de Fortificação de Transição, em pleno século XVII, não condiz com o tipo de armas de fogo que se usava na Europa, a artilharia pirobalística com poder de destruição.

As duas fortificações do tipo de Transição foram o Forte Real do Bom Jesus e o Forte de Nossa Senhora de Nazaré. O Forte Real do Bom Jesus, construído em 1630, apesar de contar com baluartes e ter a estrutura composta por reparo com escarpa em talude, foi considerado uma fortificação de Transição. A análise das suas características físicas revelou que seus baluartes eram atípicos; seu formato era ambíguo, não sendo evidente qual polígono regular deu origem à fortificação; contava com obras externas típicas da Fortificação de Transição (barbacã), e não apresentava defesa completa, tinha linhas flancantes, mas que não envolviam toda a fortificação. O Forte de Nossa Senhora de Nazaré, por sua vez, construído em 1631, também foi classificado como Fortificação de Transição, pois não contava com baluartes modernos e, tinha linhas flancantes em apenas uma cortina. 
A outra fortificação construída durante a presença dos holandeses e analisada nesse trabalho, o Forte de São Francisco de Xavier de Gaibu apresentava, por sua vez, características físicas coincidentes com aquela da Fortificação Moderna. Esse Forte, construído em 1634, era formado por uma estrutura maciça composta por reparo, com escarpa em talude, de baixa altura, não tinha baluartes e era de pequena dimensão (cerca de $20 \mathrm{~m}$ de diâmetro). Esse modelo não era considerado de muita capacidade de defesa.

Em síntese, do ponto de vista da transformação tecnológica, durante a permanência dos holandeses, observa-se que os portugueses optaram novamente por utilizar duas diferentes técnicas. Num primeiro momento, em 1630 e 1631 , construíram duas Fortificações de Transição: Forte Real do Bom Jesus e o Forte de Nossa Senhora de Nazaré. Num segundo momento, a partir de 1634, construíram uma Fortificação Moderna. Nesse período também se pode falar em transformação tecnológica; no entanto, verifica-se que os portugueses voltaram a utilizar o tipo de Transição, apesar de já terem construído Fortificações Modernas na Capitania, anteriormente. Parece que houve um atraso na Capitania de Pernambuco, considerando que as Fortificações de Transição já não eram eficazes belicamente.

No entanto, do ponto de vista da transformação tecnológica como resposta à necessidade de aumentar a eficácia bélica das fortificações e do Sistema Defensivo, os formatos das Fortificações de Transição construídas possibilitaram 
um incremento à eficácia bélica do segundo Sistema Defensivo de Pernambuco. Tanto no Forte Real do Bom Jesus como no Forte de Nossa Senhora de Nazaré os formatos utilizados possibilitaram a formação de linhas flancantes, elemento não explorado do primeiro sistema defensivo (nem mesmo no modelo de Fortificação Moderna utilizado). Por outro lado, o modelo de Fortificação Moderna escolhido, nesse segundo sistema defensivo, repetindo o modelo escolhido no Sistema Defensivo anterior, não contava com linhas flancantes. O Sistema Defensivo implantado pelos portugueses em Pernambuco, durante a invasão holandesa, também apresentava baixa capacidade defensiva, porém era um pouco mais eficaz que o primeiro Sistema Defensivo.

\section{A utilização de Tratados na construção das fortificações em Pernambuco}

Continuando as nossas reflexões, especificamente sobre a utilização de Tratados pelos portugueses ao longo dos séculos XVI e XVII, vale ressaltar que os modelos oriundos de Tratados sobre fortificações foram utilizados neste segundo Sistema Defensivo. Entretanto, o modelo utilizado no Forte de São Francisco Xavier de Gaibu, em 1634 foi um modelo simplificado, sem baluartes. Consistiam em formas puras: pentágono, constituído por uma estrutura maciça composta por reparo, com escarpa em talude, de baixa altura. Nem todos os Tratados apresentam esse modelo em seu conteúdo, provavelmente por ser bem conhecido entre os profissionais envolvidos com a guerra. 


\section{CONCLUSÃO}

Como explicar a opção por um determinado produto, mesmo sabendo da sua inadequação para o fim a que se propõe? As respostas mais ordinárias seriam justificá-la a partir da falta de recursos ou do desconhecimento, ou seja, atribuindo a responsabilidade a circunstâncias alheias a sua vontade ou distante da sua capacidade de interferência. Considerando, inclusive inadequada o termo 'escolha'. Pois, de fato, a justificativa mor seria considerá-la uma imposição.

No caso das fortificações construídas em Pernambuco, no período estudado, a justificativa do desconhecimento não poderia ser aceita, haja vista todo o investimento de Portugal, enquanto Nação, para sua introdução na 'modernidade'. Desde o início do século XV, já havia, em Portugal, preceptores italianos para os nobres, além de intelectuais estrangeiros, que eram chamados pelo Governo e pela Igreja, para atuar em território português e nas colônias. Portugal também estava se preparando para defender seu Império, foram traduzidos tratados, contratados estrangeiros, enviados engenheiros para a Itália. Foi feito todo um esforço para a formação de profissionais na arte da guerra (Wehling. 1999: p. 21 e 36).

A justificativa financeira, por sua vez, não é tão simples de refutar. De fato, o Brasil era considerado uma colônia de segunda categoria, desde o século XVI e início do XVII, os interesses estavam no Oriente. Portugal não ia investir em Pernambuco. Essa justificativa econômica, na realidade, estava intimamente relacionada às questões de fundo político, Portugal ainda não estava interessado 
no Brasil, e estava lutando por suas colônias mais rentáveis do Oriente, portanto, começava a não ter condições de realizar grandes investimentos nesse território. Mas porque, então, os colonos não investiram? Não financiaram obras de fortificação mais eficazes? Afinal, a produção de açúcar de Pernambuco ainda contava com resultados satisfatórios apesar de já começar a apresentar problemas e o tráfico de escravos começava a ser uma atividade muito rentável.

Nesse segundo momento, a partir da invasão holandesa, percebeu-se um investimento dos governantes e lideranças locais na defesa de Pernambuco. Mas nada de muito mais significativo do que as fortificações construídas no momento anterior (primeiro sistema defensivo). Foram construídas oito fortificações, todas também pequenas e frágeis, no entanto, já surgiram formatos que propiciavam a formação de linhas de defesa. Os luso-brasileiros, que na fase anterior não se esforçaram para defender a Capitania, começaram a demonstrar algum interesse.

Nesse segundo momento, foram construídas oito fortificações, todas muito pequenas e frágeis, algumas com linhas de defesa. Um sistema defensivo pouco apropriado apesar do conhecimento técnico, dos recursos que se poderiam dispor e da invasão sofrida. A Capitania ainda estava desprotegida com as fortificações construídas para a proteger.

Retomando os dois conceitos de Sistema Defensivo, enquanto um dele restringia o

Sistema Defensivo a um conjunto de fortificações e estruturas de defesa; o outro 
considera que, além das fortificações, o Sistema Defensivo incorporaria as tropas e as embarcações (Tonera, 2005: p.2). Acredita-se que as escolhas tecnológicas em Pernambuco passaram pela compreensão de sistema defensivo como essa estrutura mais ampla de fortificações, embarcações e tropas. E que a ausência desses outros elementos (embarcações e tropas) impediu investimentos apropriados nas estruturas construtivas do primeiro e do segundo Sistema Defensivo.

Pode-se, portanto, concluir que apesar de ter havido uma transformação tecnológica nos tipos de fortificação utilizados na Capitania de Pernambuco, nesse segundo período (1630 a 1654): com a utilização de configurações geométricas que propiciam o uso de linhas flancantes, e utilização de modelo moderno, representando, portanto, um aumento da eficácia bélica das fortificações; essa transformação partiu de fortificações obsoletas (Fortificação de Transição) para outras também obsoleta (Fortificação de Transição e Moderna simplificada, sem baluarte). O tipo de Transição com linhas flancantes, assim como o modelo simplificado do tipo de fortificação Moderna tinha baixa eficácia bélica.

\section{REFERÊNCIAS BIBLIOGRÁFICAS}

ALBUQUERQUE, Marcos; LUCENA, Veleda, et all. Fortes de Pernambuco: imagens do passado e do presente. Recife: Graftorre, 1999. 204p.

ALBUQUERQUE, Marcos; LUCENA, Veleda. Arraial Novo do Bom Jesus. Consolidando um processo, iniciando um futuro. Recife, Graftorre, 1997. 225p. 
ALBUQUERQUE, Marcos; LUCENA, Veleda. Forte Real do Bom Jesus: resgate arqueológico de um sítio histórico. Recife: CEPE, 1988. 64p.

CAVALCANTI, Vanildo Bezerra. Recife do Corpo Santo. $2^{\text {a }}$. ed. Recife: Bagaço, 2009.397p.

COELHO, Duarte de Albuquerque. Memórias diárias da guerra do Brasil: 1630-1638. 2a ed. Recife, Fundação de Cultura da Ciade do Recife, 1982. 366p.

DANTAS, José Robinson Alcoforado; LIMA FILHO, Clóvis. Síntese da Geologia de Pernambuco. Departamento Nacional de Produção Mineral. $4^{\circ}$ Distrito, Pernambuco. 2006. Acessado em 18/08/2014 pelo site http://www.dnpm-pe.gov.br/Sint_PE/Indice.php.

DÜRER, Albrecht. Instruction sur la fortification des villes, bourgs et chateaux. Nuremberg, 1527. 104p.

GOLDMAN, Nicolas. La Nouvelle Fortification. Leiden, 1645. 224p.

Guia de inventário - Fortificações medievais e modernas. Sacavém: IHRU/SIPA, 2015.120p.

MENEZES, José Luiz Mota. RODRIGUES, Maria do Rosário Rosa. Fortificações portuguesas no Nordeste do Brasil. Séculos XVI, XVII e XVIII. Recife: Pool. Editorial S/A, 1986. 158p.

SCAMOZZI, Vicenzo. L' Idea della Architettura Universale. Veneza, 1615. 391p. Schumann, 1972: p. 34).

TONERA, Roberto. O Sistema Defensivo da Ilha de Santa Catarina - Brasil: Criação, Abandono e Recuperação. Conferência proferida no 1er. Seminario regional de ciudades amuralladas - 6 e 7 de abril de 2005, Montevideo, Uruguay.

http://www.fortalezas.ufsc.br/6seminario/index.php

WEHLING, Arno. WEHLING, Maria José C. M. Formação do Brasil colonial. Rio de Janeiro: Nova Fronteira, 1999. 401p. 